\title{
Pour en lire plus : Formation entre terre et mer.
} Alternance écoformatrice.

\section{Marie-Claire Domasik-Bilocq}

\section{(2) OpenEdition \\ Journals}

Édition électronique

URL : http://journals.openedition.org/ere/6671

DOI : $10.4000 /$ ere.6671

ISSN : 2561-2271

Éditeur

Centr'ERE

Référence électronique

Marie-Claire Domasik-Bilocq, «Pour en lire plus : Formation entre terre et mer. Alternance

écoformatrice. », Éducation relative à l'environnement [En ligne], Volume 3 | 2002, mis en ligne le 20

mars 2002, consulté le 16 avril 2021. URL : http://journals.openedition.org/ere/6671 ; DOI : https://

doi.org/10.4000/ere.6671

Ce document a été généré automatiquement le 16 avril 2021. 
Pour en lire plus : Formation entre terre et mer. Alternance écoformatrice.

Marie-Claire Domasik-Bilocq

RÉFÉRENCE

Dominique Cottereau (2001). Formation entre terre et mer. Alternance écoformatrice. Paris : Éditions L'Harmattan. 


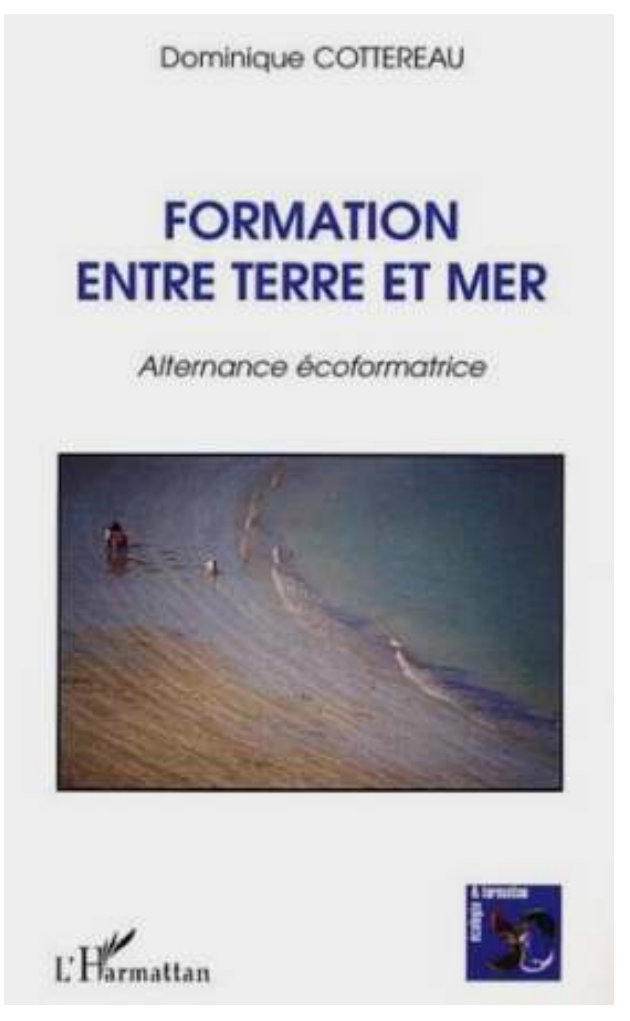

1 Former une conscience éco-logique en alternant le travail de la pensée réflexive sur l'environnement avec la rêverie et la sensibilité de l'imaginaire créateur, tel est l'objectif majeur de Dominique Cottereau.

2 Pour elle, un postulat, celui de l'importance de l'affectif dans cette relation de l'être à la nature. L'enfant doit avoir du temps pour vivre pleinement son milieu, il bénéficiera de certains moments de rencontre libres afin d'établir une relation personnelle avec l'environnement avant de pouvoir envisager des actions à mener en sa faveur.

3 Dans un style empreint d'une grande émotivité, l'auteure explore, interprète le discours et le vécu de trois enfants de CM2 vivant trois semaines de «classe environnement » dans le milieu maritime breton. Elle nous donne sa vision de la rencontre enfant / environnement.

4 Après avoir analysé les jeux et le discours d'un enfant ayant vécu le séjour dans une perspective traditionnelle de classe d'environnement et de deux autres profitant d'une alternance écoformatrice faite de moments d'études, de loisirs et de jeux libres, l'auteure nous donne son interprétation de leur évolution durant ces trois semaines.

5 Le premier, Florian, connaît le monde maritime des vacances. Il aborde, ici, l'estran de façon rationnelle, même si l'approche est interactive. Pour lui deux mondes différents, celui des vacances, plus hédonique, plus ludique et celui des apprentissages obligatoires qui lui laisse de nombreux regrets. L'auteur analyse cette rencontre comme désorganisante pour l'enfant. Florian ne peut, lors de ce séjour, incorporer ce milieu maritime vécu lors des vacances. Dans ce contexte trop organisé, trop peu ludique, il opte pour un conformisme réducteur.

6 Les deux autres, Pierre et Océane, ont l'occasion de vivre intensément leurs moments de liberté sur l'estran. Pour le garçon qui a une grande expérience du milieu maritime, une nouvelle rencontre : la matière. Il ramasse des pierres blanches et brillantes dont il évoque les faces cachées. Dominique Cottereau conclut à une «complexification de 
l'être par intégration d'éléments nouveaux puisés dans l'environnement " et une rencontre avec sa propre intériorité. La petite fille apprivoise progressivement la mer et le vent. Elle l'exprime avec beaucoup d'affectivité dans un poème ou elle personnifie la mer. L'auteur insiste ici sur la possibilité qui est donnée à l'imaginaire de s'exprimer. La fonction éco-logique s'enrichit de la fonction symbolique et permet «la mise en forme de son rapport au monde». Une relation plus intime se crée avec la mer et Océane exprime le voeu de lui venir en aide, preuve d'une progression de la conscience citoyenne.

7 Dominique Cottereau prône ainsi une écoformation qui ne transforme pas les pédagogies existantes, mais qui mette en valeur des formes éducatives trop souvent accessoires telles "l'imaginaire créateur, le sens du jeu, l'écoute sensible des éléments ».

Ce livre empreint d'émotion, d'introversion, de permanente référence à Bachelard nous laisse entrevoir les fondements de la relation de l'être à son environnement comme principe de base de l'éducation relative à l'environnement. Pour valoriser l'alternance écoformatrice, l'auteur nous fait son vécu, de l'interprétation des jeux et du discours des enfants qu'elle anime. Elle explore presque exclusivement l'aspect affectif de la rencontre. Or, dans cette spirale du développement de la personne et ses relations à l'environnement, les éléments cognitifs, sociaux et éthiques devraient également être valorisés.

\section{AUTEUR}

\section{MARIE-CLAIRE DOMASIK-BILOCQ}

Fondation Universitaire Luxembourgeoise( Arlon, Belgique ) 